Muschalla, B., Rau, H., Willmund, G.D., \& Knaevelsrud, C. (2018). Work Disability in Soldiers with Posttraumatic Stress Disorder, Posttraumatic Embitterment Disorder and Not-Event-Related Common Mental Disorders. Psychological Trauma, 10, 30-35. doi: $10.1037 /$ tra0000293.

Running head: DISABILITY IN PTSD, PTED, CMD

\title{
Work Disability in Soldiers with Posttraumatic Stress Disorder, Posttraumatic Embitterment Disorder and Not-Event-Related Common Mental Disorders
}

\author{
Beate Muschalla ${ }^{1,2}$, Heinrich Rau ${ }^{2}$, Gerd Dieter Willmund ${ }^{2}$, Christine Knaevelsrud ${ }^{1}$ \\ ${ }^{1}$ Freie Universität Berlin, Clinical Psychology and Psychotherapy, Germany \\ ${ }^{2}$ German Armed Forces Hospital Berlin, Germany
}

2272 words (abstract, introduction, method, results, discussion, references), 2 tables

Brief report for publication in Psychological Trauma

Address for correspondence:

Dr. Beate Muschalla

Freie Universität Berlin, Clinical Psychology and Psychotherapy,

Habelschwerdter Allee 45, 14195 Berlin, Germany

Email: beate.muschalla@gmx.de 


\title{
Work Disability in Soldiers with Posttraumatic Stress Disorder, Posttraumatic Embitterment Disorder and Not-Event-Related Common Mental Disorders
}

\begin{abstract}
Objective: Posttraumatic mental disorders may occur with different affect qualities. Best known is posttraumatic stress disorder (PTSD), a conditioned anxiety reaction with intrusions. Another event-related mental disorder is posttraumatic embitterment (PTED), characterized by affect of embitterment and thoughts of revenge, occurring after an event deeply hurting basic believes. Knowing about associated disability is important for treatment and sociomedical decisions. This is the first study to explore work- disability in patients with PTSD, PTED and not-event-related common mental disorder (CMD).
\end{abstract}

Methods: In this observational study 101 soldiers $(85 \%$ men, 31 years, $50 \%$ experienced expedition abroad) with different mental disorders were investigated concerning common mental disorders (MINI) and accompanying work capacity impairment (Mini-ICF-APP). Interviews were conducted by a state-licensed psychotherapist with expertise in socio-medical description of (work) capacity impairment. Patients with PTSD, PTED, and other CMD were compared concerning their degrees and pattern of work capacity impairment.

Results: PTSD patients $(\mathrm{n}=23)$ were more strongly impaired in mobility as compared to patients with other CMD $(n=64)$ or PTED. Patients with PTED $(n=14)$ were more impaired in interactional capacities (contacts with others, group integration) as compared to patients with other CMD or PTSD.

Conclusions: PTSD patients need support to improve mobility in (work-relevant) traffic situations. Apart from this, they are not specifically more or less impaired than patients with other CMD. PTED patients should get attention concerning their interactional problems as these may disturb esprit de corps which is an essential requirement for service in the armed forces. 
Keywords: posttraumatic disorders, trauma, impairment, work ability, soldiers 


\section{Posttraumatic Disorders and Work Capacity Impairment}

About $14-25 \%$ of soldiers suffer from any current mental disorder (Tamburrino et al., 2015; Trautmann et al., 2016; Zamorski et al., 2016). A small number is suffering from posttraumatic disorders of different qualities, which are associated with different types of events:

First, soldiers work in environments in which they may be exposed to life-threatening events, e.g. in foreign missions or military training. A small number of soldiers $(1.2-8.0 \%)$ develop symptoms of posttraumatic stress disorders (PTSD, F 43.1 according to ICD-10, WHO, 1992) in the aftermath of such life-threatening events (Trautmann et al., 2016; Zamorski et al., 2016). A posttraumatic stress disorder is a conditioned reaction with the core symptoms of anxiety, hyperarousal and intrusions. There must have been a critical event that was life-threatening, exceptional, and invariably leading to acute distress and severe anxiety.

Secondly, soldiers are faced with high demands for group integration and complying with rules in their daily service. An important basic belief in soldiers' life is that one has to be perfectly reliable and loyal to comrades, even under conditions of life threat. Events of injustice may appear and hurt these basic believes. When normal negative life events (such as injustice) are perceived as deeply unfair or disloyal and violate basic believes, adjustment disorders of the type posttraumatic embitterment disorders (PTED, F 43.8 according to ICD10) may occur. It is defined by specific psychopathology (deep embitterment and thoughts or action of revenge which are more than normal anger) different from PTSD, and has a specific etiology. In case of PTED, basic believes and values of life (e.g. believe in a just world or loyalty) are hurt by perceived injustice events. This can be events like a sudden termination, partner cheating on or anything else. In case of PTSD on the contrary, a life-threatening event causes stimulus-related panic anxiety, intrusion, hyperarousal. The leading symptoms of PTED are a complex negative emotional state of embitterment, anger, sadness, thoughts of revenge, helplessness, intrusive memories, restlessness, but also a normal affect when 
distracted (Linden, Baumann, Rotter \& Schippan, 2008; Linden \& Maercker, 2011).

Situations reported are often characterized by perceived interpersonal injustice, missing social support or disloyalty (Sensky, Salimu, Ballard \& Pereira, 2015). In military health research, embitterment has been discussed along with the concept of moral injury (Bryan, 2016). Embitterment at work has also been found to be associated with sickness absence (Sensky et al., 2015).

Like all mental disorders, event-related disorders may become chronic and come along with disability. Disability becomes obvious with problems fulfilling daily living activities and especially work activities due to impairment in psychological capacities. In mental disorders, capacity disorders are the observable correlate of disability. Disability in this sense (WHO, 2001) does not lie in the person, but manifests in daily activities under certain requirements, e.g. work capacity disorders. Therapy of mental disorders should not only focus on reducing symptom load, but also on training and restoring psychological capacities, or environmental support, e.g. workplace adjustment. Furthermore, description of the capacity status (and possible illness-related impairment) is needed for answering socio-medical questions such as work ability. To follow these aims, psychological capacity must be described differentiatedly and adjusted to the context.

In this study, we focus on mental-health-related capacity impairment in the military work context. The question is whether PTED, PTSD and not-event-related common mental disorders (CMD) come along with different work capacity impairment. Evidence on capacity impairment in different mental disorders is until now scarce (Muschalla, 2016). This study is the first to explore whether PTSD, PTED and other CMD are accompanied by different levels of capacity impairment, and whether capacity impairment are qualitatively different. The study has been done in a sample of soldiers who were presently in inpatient mental health treatment. Results will offer hints which psychological capacity dimensions may be of special relevance for mental health treatment and work ability description in the military setting. 


\section{Method}

\section{Procedure}

A convenient sample of patients (all soldiers) from the psychotherapeutic unit of a German army hospital were asked for voluntary participation in an interview assessment on mental health problems and capacity impairment. They were investigated concerning mental disorders (MINI, Sheehan et al., 1994) and accompanying work capacity impairment (MiniICF-APP, Linden, Baron \& Muschalla, 2015) in a structured interview. Additionally, the patients were asked for their subjective work ability according to the Work Ability Index (WAI, Tuomi, Ilmarinen, Jahkola, Katajarinne \& Tulkki, 1998).

Soldiers are sent into army hospital by their primary military physician, due to different reasons: They come to a planned therapy they have already been waiting for, or within an interval therapy, or for acute treatment, or for differential diagnostic purposes and outpatient treatment planning. All patients we saw in this study were patients who were able to follow a 90 minutes conversation, and for whom the question of work ability was realistic. Severe depression, manic, or psychotic symptomatology were exclusion criteria. Patients were invited personally by the nurses to participate in the facultative interview. $80 \%$ of the initially invited patients participated in the interview. From 103 investigated patients, two were excluded from analysis because they fulfilled criteria of both PTED and PTSD and could not be certainly assigned to a distinct group of event-related mental disorder (PTED or PTSD).

\section{Instruments}

Diagnostic of CMD and posttraumatic disorders. Diagnoses of common mental disorders were assessed with the DSM-based internationally established Mini International Neuropsychiatric Interview MINI (Sheehan et al., 1994). This semi-structured interview covers the range of the most prominent common mental disorders, i.e. affective disorders, 
addictions disorders, and anxiety disorders, including PTSD. For differential diagnostic purposes, i.e. to distinguish PTSD and PTED, the evaluated interview for posttraumatic embitterment disorders was used (Linden et al., 2008). It has good sensitivity (94\%) and specifity $(92 \%)$.

Work-relevant Capacity Impairment. The differentiated description of illnessrelated work capacity impairment was operationalized with the Mini-ICF-APP. The MiniICF-APP capacity rating is an internationally validated observer rating for the description of (work) capacity impairment in mental disorders. It showed good interrater-reliabilities (kappa .70 - .90) and was validated with the Groningen Social Disability Interview (Balestrieri et al., 2013; Baron \& Linden 2009; Linden et al., 2009, 2015; Molodynski et al., 2013; Muschalla, 2016). It has become a recommended instrument in social medicine for work ability description purposes (DGPM, 2012; DRV, 2012; SGVP, 2012). The MiniICF-APP covers thirteen dimensions of capacities which may be impaired due to mental disorders (Table 1). For quantifying capacity impairment, a specific reference context is needed. In this present study capacity impairment is rated in respect to the "present or last workplace the patient carries out in his service in the German Armed Forces". The impairment rating was done after collecting information on the military rank, job position, concrete work demands, and illness-related impairments in fulfilling the work demands in the interview (Linden et al., 2015). The interview on capacity impairment can be done in about 45 minutes. For each capacity dimension, the impairment degree is rated $0=$ no impairment, 1 = mild impairment, i.e. there are some difficulties for the person to fulfill the demands but there are no negative consequences, 2 = relevant impairment, i.e. there are visible problems in fulfilling the demands, $3=$ severe impairment, i.e. help from others is needed regularly in order to fulfill the demands and activities, $4=$ full impairment, i.e. no respective activity is possible, complete dispensation is necessary. The rating is a clinical expert rating, i.e. the interviewer has to rate the degree of impairments on the basis of his 
observation and the information on capacity impairment explored from the patient in the structured interview. The rater is a state licensed psychotherapist with ten years of expertise in psychosomatic rehabilitation diagnostic and socio-medical work-ability description.

[insert table 1 about here]

Additionally to the observer-rated work capacity impairment, the patients were asked for their subjective work ability with three questions from the Work Ability Index (WAI, Tuomi et al., 1998). They were asked for a rating on their present global work ability relative to their best work ability ever (rating 0 very bad - 10 best), concerning the present global work ability, and their mental and physical work ability (1 very bad - 5 very good). Finally, the patients were asked for their duration of sick leave presently and cumulated sick leave duration over the past 12 months.

\section{Participants}

Participants were in most cases men $(85 \%)$ of younger age $(M=31.0(S D=9.4)$ years); 50\% had already been abroad for foreign missions. Patients with PTSD had on average 2.9 MINI diagnoses, patients with CMD only 1.6 (Table 2). Comorbidities in diagnostic interviews must partly be understood as a methodological artefact because interviews count diagnostic criteria and describe syndromes (Linden \& Muschalla, 2012). Therefore the most important criterion for group differentiation in this study is the eventrelatedness (event-related versus not event-related disorder), and within the event-related disorders the quality of psychopathology: embitterment (PTED) or anxiety (PTSD). In case a patient had a PTSD or PTED diagnosis in the MINI interview, s/he belongs to the group of PTSD or PTED (and not CMD).

Sociodemographic and work-related characteristics of the three groups (PTSD, PTED, CMD) are shown in Table 2.

[insert table 2 about here] 


\section{Statistical analysis}

Data analysis was done using the IBM SPSS statistics program version 23.

Analysis of variance was calculated for comparison of capacity impairments in patients with PTSD, PTED, and those with other common mental disorders (CMD).

\section{Results}

Patients with PTSD $(n=23)$ had most often experiences with military missions abroad (Table 2). This is due to the fact that life threatening events which may trigger PTSD most often happen in military missions abroad, rather than in the home country. PTED and CMD are not etiologically related to life-threatening events. These patients have not been away on military missions as frequently as the PTSD group.

PTED $(n=14)$ was in 10 cases associated with a military situation, such as perceived injustice through a supervisor, and in 4 cases associated with the private or family domain, such as interpersonal injustice in private relationships. Military rank was not systematically associated with the occurrence of PTED.

Patients with PTSD were similarly impaired like patients with other CMD $(n=64)$ over almost all capacity dimensions (Table 3). PTSD patients were significantly more impaired in mobility as compared to patients with other CMD or PTED.

Patients with PTED however were significantly more impaired in interactional capacities (contacts with others, group integration) as compared to patients with other CMD or with PTSD. PTED patients tend to perceive their mental (but not their physical) work ability more impaired than patients with CMD or PTSD (Table 2). [insert Table 3 about here]

\section{Discussion}


Patients with different types of event-related disorders are differently impaired in work-relevant psychological capacities. PTSD patients react with phobic avoidance. They may need support in order to improve mobility in all-day and military traffic situations. Apart from this, they are not specifically more or less impaired than patients with other CMD. PTED patients have interactional problems. These are especially relevant in the military service as team skills are of great importance (Annett, Cunningham \& Mathias-Jones, 2000; Mjelde, Smith, Lunde \& Espevik, 2016; Sandal, 1989) and interactional capacity impairment may disturb esprit de corps. For treatment of PTED patients, interaction-oriented aims might be focused, e.g. restoring an active and supportive attitude towards comrades, or problem and conflict solving in a company team.

\section{Limitation and strength of the study and further action}

This study is a cross-sectional observation study and data cannot suggest causal interpretations. A strength of the study is that the semi-structured research interviews have been conducted by a trained clinician and thus differential diagnosis (PTED, PTSD, CMD) can be expected to be clinically valid.

The small sample size limits statistical power on difference detection. The results show us where the most obvious differences in capacity impairment may be expected between PTSD, PTED and CMD.

Further epidemiological research should explore the distribution of capacity impairment in different patient groups more routinely. A next further research question is whether PTED patients with dominant interactional problems should be treated with interactional capacity trainings (e.g. Hinsch \& Pfingsten, 2007). Or should for PTED patients such capacity trainings be combined with wisdom therapy? Wisdom therapy has been found to be specifically helpful for patients with embitterment problems (Linden et al., 2011).

The concept of capacity (impairment) may in general be useful for motivating patients to start thinking about treatment of their mental health problems. The capacity perspective 
does not focus on symptoms and functional deficits, but on activities and daily living. It may therefore offer new perspectives to start working on the mental health topic: not having to speak about symptoms and feelings, but - supporting of the concept of "mental fitness" (Alliger-Horn \& Zimmermann, 2017) - about actions in daily living. Therefore the capacity dimensions of the Mini-ICF-APP may be understood as an outline for a medical evidence on the capacity level (beside the symptomatic evidence). It allows a more differentiated description of capacity level than global work ability measures (e.g. Work Ability Index, Tuomi et al., 1998) and can also be used to describe resources, i.e. capacities which are unimpaired. These may be used to compensate problems with other capacities. Also workplace and personal development may profit from a differentiated description of soldiers capacity profiles: Capacity profiles are useful for finding the right person-job-fit (French, 1973), or - in case of illness - finding possibilities for workplace adjustment in the sense of a context-oriented therapy. For example, a soldier who is impaired in planning and structuring but not in contact is taken out of the logistic section and transferred into a public relations team. Thus, complete sick leave might be avoided and the soldiers may stay in service despite a mental health problem and capacity deficit. 


\section{References}

Alliger-Horn, C., \& Zimmermann, P. (2017). Präventive und psychotherapeutische Praxis der Versorgung einsatzbedingter psychischer Erkrankungen im Rahmen der Bundeswehr. Verhaltenstherapie, 27, 44-52.

Annett, J., Cunningham, D., \& Mathias-Jones, P. (2000). A method for measuring team skills. Ergonomics, 43, 1076-1094.

Balestrieri, M., Isola, M., Bonn, R., Tam, T., Vio, M., Linden, M., \& Maso, E. (2013). Validation of an Italian version of the Mini-ICF-APP, a short instrument for rating activity and participation restrictions in psychiatric disorders. Epidemiology and Psychiatric Sciences, 22, 81-91.

Baron, S., \& Linden, M. (2009). Disorders of functions and disorders or capacity in relation to sick leave in mental disorders. International Journal of Social Psychiatry, 55, 57-63.

Bryan, C.J. (2016). Moral injury, posttraumatic stress, and embitterment among military personnel. Abstracts of the $3^{\text {rd }}$ international Conference Embitterment and Mental Health, Berlin: DeGPT, DGPPR, dgpm, p. 13.

DGPM. (2012) Leitlinie zur Begutachtung psychischer und psychosomatischer Erkrankungen. Sk2-Leitlinie, AWMF-Leitlinien-Register Nr. 051/029, Stand: 31.03 .2012 (gültig bis: 31.03.2017). Deutsche Gesellschaft für Psychosomatische Medizin und Ärztliche Psychotherapie e.V., DKPM Deutsches Kollegium für Psychosomatische Medizin. Online available: www.awmf.org

DRV. (2012). Leitlinien für die sozialmedizinische Begutachtung. Sozialmedizinische Beurteilung bei psychischen und Verhaltensstörungen. Deutsche Rentenversicherung Bund, Berlin.

French, J.R.P Jr. (1973). Person role fit. Occupational Mental Health, 3, 15-20.

Hinsch, R., \& Pfingsten, U. (2007). Das Gruppentraining Sozialer Kompetenzen (GSK). Weinheim: Beltz / PVU. 
Linden, M., Baron, S., \& Muschalla, B. (2009, 2015). Mini-ICF-Rating für psychische Störungen (Mini-ICF-APP). Ein Kurzinstrument zur Beurteilung von Fähigkeits- bzw. Kapazitätsstörungen bei psychischen Störungen. Göttingen: Hans Huber.

Linden, M., Baron, S., Muschalla, B., \& Ostholt-Corsten, M. (2015).

Fähigkeitsbeeinträchtigungen bei psychischen Erkrankungen. Diagnostik, Therapie und sozialmedizinische Beurteilung in Anlehnung an das Mini-ICF-APP. Göttingen: Hogrefe.

Linden, M., Baron, S., \& Muschalla, B. (2015). Mini-ICF-Rating für psychische Störungen (Mini-ICF-APP). Ein Kurzinstrument zur Beurteilung von Fähigkeits- bzw. Kapazitätsstörungen bei psychischen Störungen. Göttingen: Hans Huber.

Linden, M., Baumann, K., Rotter, M., \& Schippan, B. (2008). Diagnostic criteria and the standardized diagnostic interview for posttraumatic embitterment disorder (PTED). International Journal of Psychiatry in Clinical Practice, 12, 93-96.

Linden, M., Baumann, K., Lieberei, B., Lorenz, C., \& Rotter, M. (2011). Treatment of posttraumatic embitterment disorder with cognitive behaviour therapy based on wisdom psychology and hedonia strategies. Psychotherapapy and Psychosomatics, 80, 199-205.

Linden, M., \& Maercker, A. (2011). Embitterment. Societal, psychological, and clinical perspectives. Wien: Springer.

Linden, M., \& Muschalla, B. (2012). Standardized diagnostic interviews, criteria, and algorithms for mental disorders: garbage in, garbage out. European Archives of Psychiatry and Clinical Neuroscience,262, 535-544.

Mjelde, F.V., Smith, K., Lunde, P., \& Espevik, R. (2016). Military teams - A demands for resilience. Work, 54, 283-294.

Molodynski, A., Linden, M., Juckel, G., Yeeles, K., Anderson, C., Vazquez-Montes, M., \& Burns, T. (2013). The reliability, validity, and applicability of an English language 
version of the Mini-ICF-APP. Social Psychiatry and Psychiatric Epidemiology, 48, $1347-1354$.

SGVP. (2012). Qualitätsleitlinien für psychiatrische Gutachten in der Eidgenössischen Invalidenversicherung. Schweizer Gesellschaft für Versicherungspsychiatrie und Schweizerische Gesellschaft für Psychiatrie und Psychotherapie SGPP, Bern Sandal, G.M. (1998). The effects of personality and interpersonal relations on crew performance during space simulation studies. Life Support \& Bioshere Science, 5, $461-470$.

Sensky, T., Salimu, R., Ballard, J., \& Pereira, D. (2015). Associations of chronic embitterment among NHS staff. Occupational Medicine, 65, 431-436.

Sheehan, D., Janavs, J., Baker, R., Knapp, E., Sheehan, K.H., \& Sheehan, M. (1994). MINI. Mini International Neuropsychiatric Interview. Tampa: University of South Florida. Tamburrino, M.B., Chan, P., Prescott, M., Calabrse,J., Liberzon, I., Slembarski, R., Shirley, E., Fine, T., Goto, T., Wilson, K., Derus, A., Ganocy, S., Beth Serrano, M., \& Galea, S. (2015). Baseline prevalence of Axis I diagnosis in the Ohio Army National Guard. Psychiatry Research, 226, 142-148.

Trautmann, S., Goodwin, L., Höfler, M., Jacobi, F., Strehle, J., Zimmermann, P., \& Wittchen, H.U. (2016). Prevalence and severity of mental disorders in military personnel: a standardised comparison with civilians. Epidemiology and Psychiatric Sciences, 18, ahead of print.

Tuomi, K., Ilmarinen, J., Jahkola, A., Katajarinne, L., \& Tulkki, A. (1998). Work Ability Index, 2nd revised edition. Helsinki: Finnish Institute of Occupational Health.

WHO World Health Organization. (2001). International Classification of Functioning, Disability and Health: ICF. Geneva: World Health Organization.

WHO World Health Organization. (1992). International Statistical Classification of Diseases and Related Health Problems, $10^{\text {th }}$ revision. Geneva: World Health Organization. 
Zamorski, M.A., Bennett, R.E., Rusu, C., Weeks, M., Boulos, D., \& Garber, B.G. (2016).

Prevalence of Past-Year Mental Disorders in the Canadian Armed Forces, 2002-2013.

Canadian Journal of Psychiatry, 61, 26S-35S. doi: 10.1177/0706743716628854. 
Table 1.

Capacity dimensions of the Mini-ICF-APP (according to Linden et al., 2009, 2015)

Adherence to regulations

Capacity to obey rules, routines and dates, which is especially relevant in all military sections

Planning and structuring tasks

Capacity of structuring ones work duties in a senseful manner, daily duties as well as longerlasting projects, organizing events or material

Flexibility

Capacity to show different behavior according to situation, place and persons; being able to switch from one routine task to another issue or task which suddenly comes up

Applying expertise

Being able to apply ones knowledge and expertise to fulfill the current duties

Capacity to judge and decide

Capacity of understanding and judging on (new) situations or processes, combining issues, options and consequences, making contextual senseful decisions

Proactivity

Actively acting in order to initiate processes or projects by oneself (contrary: reacting)

Endurance

Staying in one task or service as long as necessary, with stable level of performance

Assertiveness

Being able to express ones opinion or defend a position, taking in account interactional rules

Contacts with others

Capacity to make short contacts and small talk with the aim to come in contact with other

persons

Group integration

Capacity to fit into a group, show behavior according to the group norms, presenting oneself in the group according to one's place or formal rank position

Dyadic relationships

Capacity to give emotional support and build up and maintain a trustful personal relationship

Self-care

Being able to keep one's body healthy (healthy nutrition, physical exercise) and show acceptable outer appearance according to the norm

Mobility

Being able to reach each relevant place by using any relevant transportation mean (train, car, air plane, tank etc.) 
Table 2

Sample characteristics. Depending on the type of variable, means (standard deviation) or absolute (in brackets relative) frequencies are reported. Group comparison with ANOVA with Post-hoc tests, Bonferroni corrected, ${ }^{a, b, c}$ show the p-values. $X^{2}$-Test has been calculated for comparison of frequencies in cases of categorical variables, here the overall p-values are reported.

\begin{tabular}{|c|c|c|c|c|}
\hline & $\frac{\frac{\text { Patients with }}{\text { posttraumatic }}}{\frac{\text { stress disorder }}{(\text { PTSD })}}$ & $\begin{array}{c}\frac{\text { Patients with }}{\text { posttraumatic }} \\
\frac{\text { embitterment }}{\text { disorder (PTED) }} \\
(n=14)\end{array}$ & $\frac{\frac{\text { Patients with }}{\text { other common }}}{\underline{\text { mental }}} \frac{\text { disorders }}{\frac{(\mathrm{CMD})}{(n=64)}}$ & $\begin{array}{l}\text { Significance of } \\
\text { differences between the } \\
\text { groups in } \\
p \\
{ }^{\text {a }} \text { PTSD vs PTED } \\
{ }^{\mathrm{b}} \text { CMD vs PTED } \\
{ }^{\mathrm{c}} \text { CMD vs PTSD }\end{array}$ \\
\hline Age & $33.3(7.5)$ & $33.5(7.1)$ & $29.5(10.2)$ & ${ }^{\mathrm{a}} 1.000,,^{\mathrm{b}} .458,,^{\mathrm{c}} .287$ \\
\hline Gender: male & $22(95 \%)$ & $14(100 \%)$ & $50(78 \%)$ & .031 \\
\hline Military rank & $0.74(0.62)$ & $1.07(0.73)$ & $0.86(0.61)$ & $\mathrm{a} .372,{ }^{\mathrm{b}} .774,{ }^{\mathrm{c}} 1.000$ \\
\hline Personnel (0) & $8(35 \%)$ & $3(21 \%)$ & $17(27 \%)$ & \\
\hline Subofficers (1) & $13(56 \%)$ & $7(50 \%)$ & $39(61 \%)$ & \\
\hline Officers (2) & $2(9 \%)$ & $4(29 \%)$ & $8(12 \%)$ & \\
\hline $\begin{array}{l}\text { Participated in } \\
\text { military mission } \\
\text { abroad }\end{array}$ & $20(87 \%)$ & $7(50 \%)$ & $23(36 \%)$ & .000 \\
\hline $\begin{array}{l}\text { Number of military } \\
\text { missions abroad }\end{array}$ & $2.5(2.0)$ & $1.3(1.7)$ & $0.75(1.3)$ & ${ }^{\mathrm{a}} .060,{ }^{\mathrm{b}} .724,,^{\mathrm{c}} .000$ \\
\hline $\begin{array}{l}\text { Presently not in } \\
\text { treatment for mental } \\
\text { disorder }\end{array}$ & $2(9 \%)$ & $3(21 \%)$ & $25(39 \%)$ & .023 \\
\hline $\begin{array}{l}\text { Number of } \\
\text { comorbid diagnoses } \\
\text { according to MINI }\end{array}$ & $2.9(1.1)$ & $2.6(1.4)$ & $1.6(1.5)$ & ${ }^{\mathrm{a}} 1.000,{ }^{\mathrm{b}} .068,{ }^{\mathrm{c}} .001$ \\
\hline $\begin{array}{l}\text { Duration of present } \\
\text { sickness absence in } \\
\text { weeks }\end{array}$ & $3.31(5.50)$ & $6.43(9.41)$ & $5.51(10.18)$ & ${ }^{\mathrm{a}} .962,{ }^{\mathrm{b}} 1.000,{ }^{\mathrm{c}} .990$ \\
\hline $\begin{array}{l}\text { Duration of sickness } \\
\text { absence in the past } \\
12 \text { months in weeks }\end{array}$ & $10.14(11.80)$ & $12.18(11.84)$ & $9.09(11.39)$ & ${ }^{\mathrm{a}} 1.000,{ }^{\mathrm{b}} 1.000,{ }^{\mathrm{c}} 1.000$ \\
\hline $\begin{array}{l}\text { Global work ability } \\
\text { presently as } \\
\text { compared to best } \\
\text { ever (WAI } 0-10 \text { ) }\end{array}$ & $4.87(1.84)$ & $2.93(3.15)$ & $4.56(2.70)$ & ${ }^{\mathrm{a}} .087,{ }^{\mathrm{b}} .104,{ }^{\mathrm{c}} 1.000$ \\
\hline $\begin{array}{l}\text { Physical work } \\
\text { ability (WAI 1-5) }\end{array}$ & $3.30(1.15)$ & $3.69(1.25)$ & $3.42(1.12)$ & ${ }^{\mathrm{a}} .995,{ }^{\mathrm{b}} 1.000,{ }^{\mathrm{c}} 1.000$ \\
\hline $\begin{array}{l}\text { Mental work ability } \\
\text { (WAI 1-5) }\end{array}$ & $2.57(0.95)$ & $1.85(1.21)$ & $2.58(1.15)$ & ${ }^{\mathrm{a}} .200,{ }^{\mathrm{b}} .101,{ }^{\mathrm{c}} 1.000$ \\
\hline
\end{tabular}


Table 3

Capacity impairment in soldiers with posttraumatic stress disorder (PTSD), or posttraumatic embitterment disorder (PTED), or other common mental disorders (CMD). First line shows the absolute (in brackets the relative) frequencies of patients with high impairment (rating 34), p-values of $X^{2}$-Test. Second line shows the means (standard deviation) of capacity impairment, p-values of ANOVA Post hoc tests are reported ${ }^{(a, b, c)}$, Bonferroni corrected.

\begin{tabular}{|c|c|c|c|c|}
\hline & 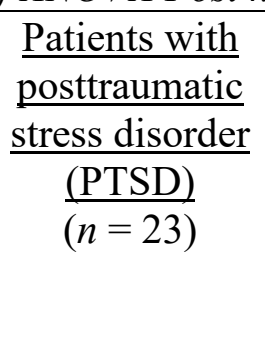 & 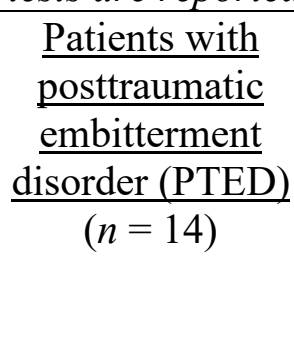 & $\frac{\frac{\text { Patients with }}{\text { other common }}}{\frac{(\mathrm{CMD})}{(n=64)}}$ & $\begin{array}{l}\text { Significance of } \\
\text { differences between the } \\
\text { groups } \\
p \\
{ }^{a} \text { PTSD vs PTED } \\
{ }^{\mathrm{b}} \text { CMD vs PTED } \\
{ }^{\mathrm{c}} \text { CMD vs PTSD }\end{array}$ \\
\hline Adherence to & $0(0 \%)$ & $3(21 \%)$ & $11(17 \%)$ & .084 \\
\hline regulations & $0.7(0.82)$ & $1.14(1.41)$ & $0.95(1.23)$ & a $.794^{\mathrm{b}} 1.000,^{\mathrm{c}} 1.000$ \\
\hline Planning and & $4(17 \%)$ & $4(29 \%)$ & $14(22 \%)$ & .726 \\
\hline structuring tasks & $1.00(1.20)$ & $0.93(1.54)$ & $1.13(1.25)$ & ${ }^{\mathrm{a}} 1.000,{ }^{\mathrm{b}} 1.000,{ }^{\mathrm{c}} 1.000$ \\
\hline \multirow[t]{2}{*}{ Flexibility } & $3(13 \%)$ & $4(29 \%)$ & $12(19 \%)$ & .503 \\
\hline & $1.39(1.11)$ & $1.57(1.60)$ & $1.31(1.27)$ & ${ }^{\mathrm{a}} 1.000,{ }^{\mathrm{b}} 1.000,{ }^{\mathrm{c}} 1.000$ \\
\hline \multirow[t]{2}{*}{ Applying expertise } & $2(9 \%)$ & $1(7 \%)$ & $5(8 \%)$ & .984 \\
\hline & $1.00(1.00)$ & $0.50(1.09)$ & $0.78(1.16)$ & ${ }^{\mathrm{a}} .570,{ }^{\mathrm{b}} 1.000,{ }^{\mathrm{c}} 1.000$ \\
\hline \multirow{2}{*}{$\begin{array}{l}\text { Capacity to judge and } \\
\text { decide }\end{array}$} & $1(4 \%)$ & $2(14 \%)$ & $8(13 \%)$ & .509 \\
\hline & $0.47(0.84)$ & $0.85(1.35)$ & $0.66(1.10)$ & ${ }^{\mathrm{a}} .920, \mathrm{~b}^{\mathrm{b}} 1.000,{ }^{\mathrm{c}} 1.000$ \\
\hline \multirow[t]{2}{*}{ Proactivity } & $1(4 \%)$ & $3(21 \%)$ & $8(13 \%)$ & .288 \\
\hline & $0.65(0.71)$ & $1.07(1.38)$ & $0.66(1.12)$ & ${ }^{\mathrm{a}} .766,{ }^{\mathrm{b}} .589,{ }^{\mathrm{c}} 1.000$ \\
\hline \multirow[t]{2}{*}{ Endurance } & $11(48 \%)$ & $5(36 \%)$ & $21(33 \%)$ & .438 \\
\hline & $1.87(1.42)$ & $1.71(1.63)$ & $1.56(1.39)$ & ${ }^{\mathrm{a}} 1.000,{ }^{\mathrm{b}} 1.000,{ }^{\mathrm{c}} 1.000$ \\
\hline \multirow[t]{2}{*}{ Assertiveness } & $2(9 \%)$ & $4(29 \%)$ & $5(8 \%)$ & .072 \\
\hline & $1.04(1.02)$ & $1.50(1.50)$ & $0.92(1.09)$ & a $.719,{ }^{b} .265,{ }^{c} 1.000$ \\
\hline \multirow[t]{2}{*}{ Contacts with others } & $0(0 \%)$ & $2(14 \%)$ & $3(5 \%)$ & .150 \\
\hline & $0.69(0.70)$ & $1.64(1.33)$ & $0.83(0.95)$ & ${ }^{\mathrm{a}} .014,{ }^{\mathrm{b}} .015,{ }^{\mathrm{c}} 1.000$ \\
\hline \multirow[t]{2}{*}{ Group integration } & $0(0 \%)$ & $5(36 \%)$ & $4(6 \%)$ & .001 \\
\hline & $0.69(0.76)$ & $1.71(1.65)$ & $0.72(0.95)$ & ${ }^{\mathrm{a}} .016,{ }^{\mathrm{b}} .005,{ }^{\mathrm{c}} 1.000$ \\
\hline \multirow[t]{2}{*}{ Dyadic relationships } & $1(4 \%)$ & $4(29 \%)$ & $8(13 \%)$ & .104 \\
\hline & $0.73(0.92)$ & $1.42(1.65)$ & $0.84(1.30)$ & a $.344,{ }^{b} .369,{ }^{c} 1.000$ \\
\hline \multirow{2}{*}{ Self-care } & $2(9 \%)$ & $2(14 \%)$ & $5(8 \%)$ & .743 \\
\hline & $1.00(1.00)$ & $1.21(1.18)$ & $0.75(0.94)$ & a $1.000,{ }^{b} .347,{ }^{c} .907$ \\
\hline \multirow[t]{2}{*}{ Mobility } & $2(9 \%)$ & $0(0 \%)$ & $5(8 \%)$ & .540 \\
\hline & $1.17(0.88)$ & $0.35(0.49)$ & $0.45(0.91)$ & ${ }^{\mathrm{a}} .018,{ }^{\mathrm{b}} 1.000,^{\mathrm{c}} .002$ \\
\hline
\end{tabular}

